\title{
Performance evaluation of terminal airspace system safety, delay and predictability of Muritala Mohammed International Airport, Ikeja Lagos, Nigeria
}

\author{
Ejem A. Ejem * $\mathbb{D}^{\mathbb{D}}$, Vivian N. Ikeogu *, Chinenye L. Okafor **(D), \\ P. O. Erumaka* \\ * Department of Transport Management Technology, Federal University Technology, Owerri, Nigeria \\ ejemflagospel@yahoo.com; viviroseitu234@gmail.com; edoziemg@yahoo.com \\ ** Centre for Environmental Studies and Sustainable Development, Lagos State University, Ojo, Nigeria \\ chinenyeokafor2017@yahoo.com
}

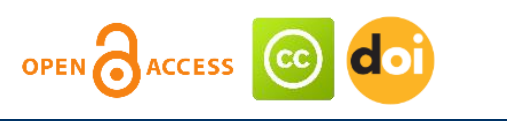

\section{Article history:}

Received: June 06, 2020

1st Revision: September 23,

2020

Accepted: November 05, 2020

\section{DOI:}

10.14254/jsdtl.2020.5-2.6

\begin{abstract}
This paper outlines a multi-dimensional useroriented performance metrics approach in evaluating the operation of the terminal airspace system to aid in the airport and airspace planning and decision making. Safety, delay and predictability metrics contribute to the analytical framework. From the findings, the occurrence of air incidence has a high severity level at departure, and arrival phases of flight, higher likelihood at the radar room and much of the incidences were as a result of faulty equipment and inherent absence of modern airspace infrastructure. Also, in Lagos terminal airspace, the number of incidences has no close correlation with the level of traffic complexity. Total schedule arrival delay ranges from 1392 minutes representing an average of 7.8-17.9 minutes per aircraft that arrived Lagos airport at that period. Besides, the total approach contact time ranges from 1-57 minutes, translating to 4.6-7.1 minutes per aircraft. However, variability in arrival time of 1-5 minutes is common from published airline arrival scheduled time. In the same vein, the variability of 1-5 minutes is common from approach contact times of aircraft. These figures indicate sound arrival predictability signature for Lagos airport. Also, departure time variability above 30 minutes is familiar from the ATC clearance time for the various routes under study. However, there is about or more $25 \%$ variability of more than 15 minutes, and this indicates possible inconsistency of predicting departure times from the times ATC clearance was acquired. Above all, the predictability of departure times in Lagos airport is weak compared to those of the arrival. Taken by it, this may be a sign of airspace congestion or ATC deficiencies at the Lagos airport. This is an indication of the lack of users' confidence in Nigeria's air transport industry to deliver just-in-time service.
\end{abstract}

Corresponding author: Ejem A. Ejem

E-mail: ejemflagospel@yahoo.com 
Keywords: terminal airspace, safety, delay, predictability and ATC.

\section{Introduction}

The safety is a critical factor in the performance of any airport across the world (Chang et al., 2015; Enoma \& Allen, 2007; Enoma et al., 2009; Leva et al., 2015; Pacheco et al., 2014; Roelen \& Blom, 2013). Despite this great interest in airport benchmarking, the authors advocated that there is limited value in simple comparisons between performance indicators. Accordingly, there is the need for exploring the effects of airport characteristics, managerial factors, and exogenous variables on airport efficiency/productivity in order to provide useful insights from the benchmarking results (Adler et al., 2013a; Humphreys and Francis, 2002; Lai et al., 2012; Sarkis, 2000; Yoshida and Fujimoto, 2004). Safety and delay are significant concerns in daily airport management, as suggested by Gillen and Morrison (2015) and Chang et al. (2015), it seems that they have not inspired researchers. This can be associated with the fact that airports are strictly regulated when it comes to safety, which may narrow the opportunities for research projects. Safety measures and delay were employed as part of operational and service quality measures were predominant among the most used, as indicated in clusters 1 and 2 of modelling the performance measurement practices in airports (Bezerraa \& Gomesb, 2018).

Airport delay can be defined as the difference between the time it could take an aircraft or passenger to be served without interference from other aircraft or passengers and the actual time it takes the aircraft or passengers to be served. Paul and Leonard (2000) remarked that delay is defined in many different ways depending upon the context. Scheduled departure and arrival delay is how late a flight departs or arrives compared to an airlines schedule. Flight can incur delays while airborne or on the ground, for example as aircraft taxi between the runway and the gate. Late arrival of one flight may cause a late departure of the next flight on the itinerary of the aircraft's arrivals and departures. (Okeudo \& Ejem, 2009).

Delay in the airport is a global issue. These delay periods impact the airport's ability to provide a consistent level of air service to the travelling public and other airport users. Besides, as aviation demand increases over time, flight delays will continue to worsen, thus further deteriorating the airport operational reliability. According to the FAA (2001), the weather is a contributing factor in $74 \%$ of air carrier delays and $30 \%$ of all accident. Weather delays cost airlines. Weather-related flight delays are one to the interaction of two factors. One, how many planes can an airport accept during a given period based on the weather (airport capacity). Two, how many planes are scheduled to arrive (airport demand) during the same given period. The most significant and standard weather variables that cause delays are low clouds and low visibility. Low visibility may be due to fog, haze, smoke and falling precipitation. When these conditions occur, planes may be spaced further apart, thus resulting in fewer planes landing in any given hour. Strong cross-winds may make some runways unstable. Thunderstorms near the airport may limit the flight paths available into and out of the airport.

Thunderstorms en-route may cause a reduction in the number of flight paths, causing delays. Heavy snow requires frequent ploughing possibly making some runways unavailable. Freezing rain and snow usually necessitate the use of anti-icing and de-icing procedures (Okeudo \& Ejem, 2009). The FAA (2002) categorises delays into gate delay, taxi-out delay, en-route (in-flight) delay, terminal delay and taxi-in delay. This is also validated by Syren (2002). Each category of delay arises when the aircraft requires more time than was scheduled. Ground delay programs, en-route capacity constraints, aircraft maintenance issues, ground services (fuel, baggage and catering), customer service issues, late aircraft crew arrival, and poor weather conditions elsewhere all contribute to surface delays.

The Nigerian Airspace Management Agency (NAMA) is essentially a service organisation relentlessly committed to providing safe and functional navigation services that will meet and given its commitment and focus, even exceed international standards. The agency maximises within s given block of airspace architecture the utilisation of available space by dynamic time-sharing and at times the segregation of airspace among the category of users based on short-term needs. Because of the need for joint use of the Nigerian airspace for civil and military purpose, co-ordination of efforts between NAMA and military authorities has become imperative. The agency also harmonises facilities and services in order to ensure efficient utilisation of natural resources. This paper tends to assess the terminal airspace 
system safety, delay and predictability of Muritala Mohammed International Airport, Ikeja Lagos, Nigeria.

\section{Methodology}

Data used in this study were obtained from a secondary source only. The secondary source includes data survey as inbound strips, outbound flight, strips, from the control tower (the air traffic control tower and the approach. The strip (outbound and inbound) is a tool used by the Air Traffic Controllers and the Approach to store information about each flight of any aircraft. It shows detailed information about any aircraft that arrives and departs the airport.

The data needed for the analysis were extracted from strips from the control tower and approach for seven days. This study investigated a typical week operation at LOS terminal characterised by the researcher as a week of optimum level of airport operation. It is based on the good daily flight in which the maximum number of aircraft can be routinely handled using visual approaches during periods of unlimited ceiling and visibility. It comprises of flight schedules from June 1 to July 7 of the year 2013 daily. Data extracted are information on Aircraft destination, Aircraft origin, aircraft start-up time, aircraft approach contact time, scheduled time of departure or estimated time of departure (ETD), actual-time departure (ATD), scheduled time of arrival or estimated time of Arrival (ETA) and the actual time of Arrival (ATA). The analytical tool used in this paper is the performance metric parameters. The delay metrics were generated for a typical day by day first averaging the result over seven days. In conducting a terminal airspace evaluation, the analysis will choose among the listed metrics based on the nature of the anticipated problem as identified by the indicator FAA (2000).

\subsection{System safety}

The purpose of this aeronautical study is to determine the effect of the modern airspace infrastructures available at the Lagos terminal airspace to the safe and efficient utilisation of the navigable airspace by aircraft and the safety of persons and property on the ground. According to Obinani (2002), over eighty per cent of air crashes all over the aviation world occur in and within the vicinity of the airport with most of them, resulting in a high rate of fatality. This figure is however alarming, and hence efforts should be ensured to put the necessary personnel and infrastructure in place to guarantee the safety of terminal navigable airspace. However, the frequency of operational error OE and operational deviation OD were the metrics employed here to indicate the current level of safety associated with Lagos terminal airspace. In effects, the facts and figures of OE and OD were not available due to lack of Enhanced Traffic Management System (ETMS) data in the Nigerian airports. Therefore structured instrument was administered to access the frequency of OE and OD occurrences.

\subsection{System delay}

Delay is categorised as arrival, departure or ground delays associated with a particular airport. The following shall be examined in this study:

\section{Arrival Delay}

These metrics indicate whether there are arrival delays associated with an airport. If significant delays are observed, then the airline arrival scheduling metric is used to determine whether the delays are associated with the airline over scheduling or an airspace problem. The metrics under study include:

1. Average Arrival Delays: Difference between the actual arrival time and the scheduled arrival time in minutes for a representative period.

2. Airport arrival scheduling: Difference of airport capacity versus scheduled arrival demand for a representative time.

\section{Departure Delay}

These metrics indicate whether there are departure delays associated with an airport. If significant delays are observed, then the airline departure scheduling metric is used to determine 
whether the delays are associated with the airline over scheduling or an airspace problem. The metrics under study include:

1. Average Departure Delays: Difference between the actual departure time and the scheduled departure time in minutes for a representative period.

2. Airport Departure Scheduling: Difference of airport capacity versus scheduled departure demand for a representative period.

3. Average Departure Fix Delay: Average difference of actual departure time with the time the flight is acquired by en-route random over each departure fix associated with the airport for a representative period.

\subsection{System predictability}

These metrics indicate whether there is significant time variability associated with a specific phase of flight. This study was restricted to the following metrics:

1. Arrival time variability: variability of arrival times for routes with five or more flights to an airport for a representative period.

2. Departure time variability: variability of departure times for routes with five or more flights to an airport for a representative period.

\section{Results and discussion}

\subsection{Analysis of terminal airspace system safety}

From the result of the survey, it was discovered that $40 \%, 32 \%$ and $28 \%$ of air traffic management personnel reported various cases of air incidences of operational error, operational deviation and other incidents respectively. These outcomes pose a severe indictment on the level of safety of the Lagos terminal airspace. The survey further assessed various factors considered paramount to terminal airspace safety as, flight profile at the point of the incidence, position function of the various ATM personnel, level of training within 12 months before the incidence, cause of the incidence, type of control offered at the time of incidence and the level of traffic complexity at the time of the incidence.

Figure 1: Level of safety with the flight profile

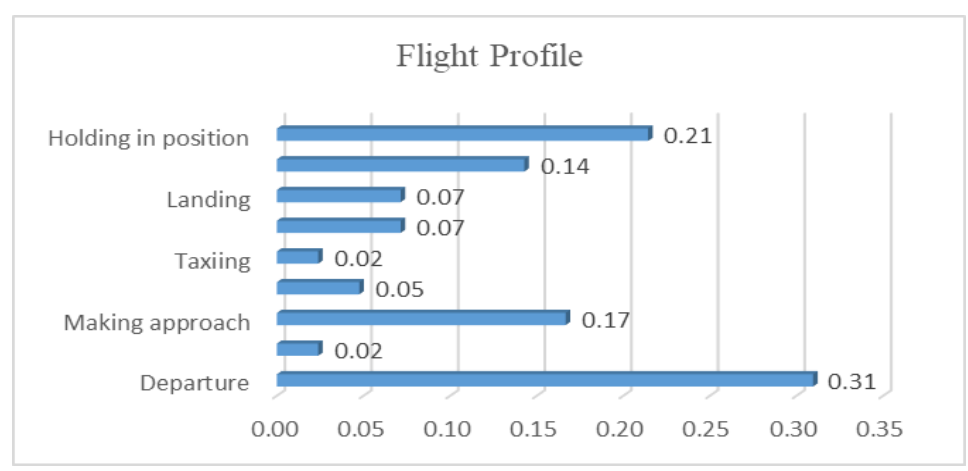

Findings reveal that during the various cases of incidence recorded, the various flight profiles of the aircraft involved in the incidences indicate 31\% were at departure phase, $2 \%$ touching down, $17 \%$ making approach, $5 \%$ at the level flight, $2 \%$ in taxing and $7 \%$ on takeoff roll. Also, none was reported at the landing phase of the flight, but $14 \%$ of the aircraft was at the climbing phase and $21 \%$ holding in position awaiting arrival clearance. More so, the various ATM personnel that reported the incidence, $32 \%$ of them were are the radar room, $3 \%$ at the control cabin, 3\% involved in sorting flight data, $16 \%$ giving clearance delivery, $13 \%$ on ground control duty. Besides, $18 \%$ of the personnel were at departure position duties, and the same figure was at arrival position duties. $45 \%$ of the ATM personnel revealed that they had undertaken various training 12 months before the incidence and $55 \%$ had no form of relevant training 12 months before the occurrence of the incidence. 
Figure 2: Level of safety with ATM position function

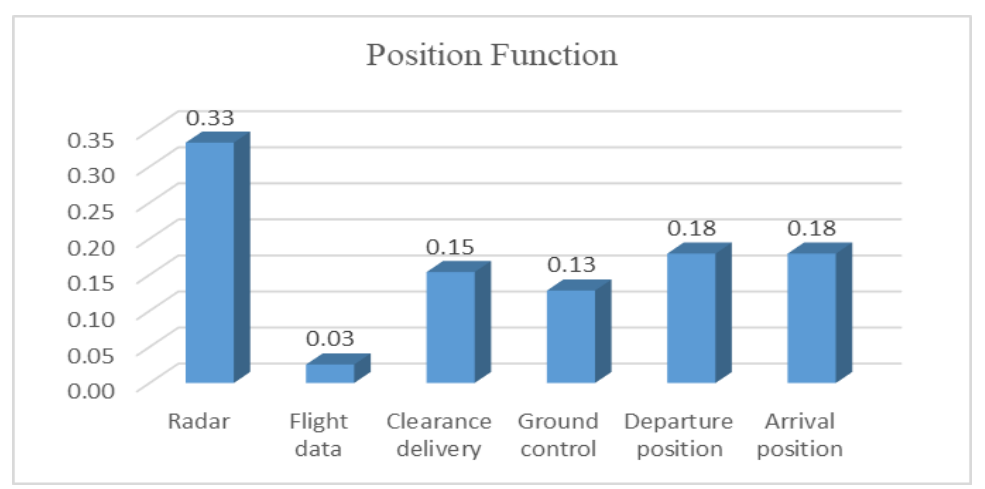

Moreover, $58 \%$ of the respondents claimed that the incidence was as a result of equipment malfunction and outright shortage. In comparison, $42 \%$ revealed that such incidences were caused by non-equipment variables such as the presence of the visitor, extraneous conversion with co-workers, mistaken phraseology during pilot-controller conversation and the likes. Also, 39\% of the staff out rayed that the said incidences happened at the instance of radar control, $45 \%$ at the tower control and $16 \%$ at non-radar control.

Figure 3: Level of safety with the type of ATM control

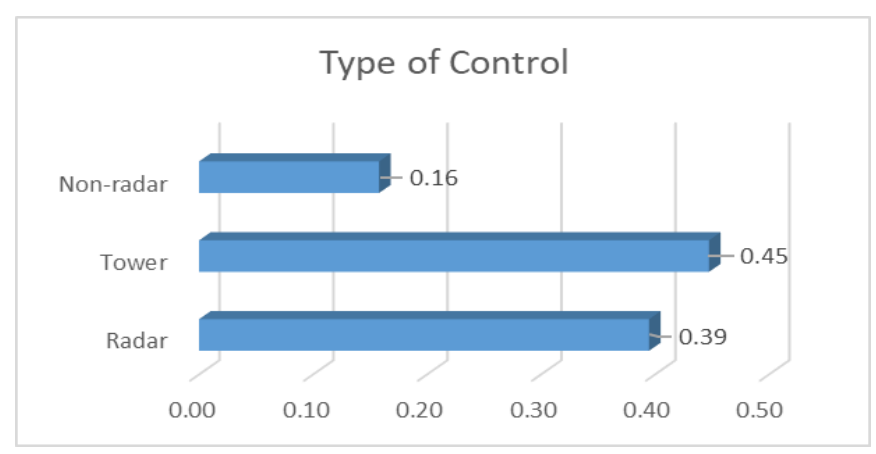

Also, it is most shocking to note that $61 \%$ of the ATM personnel reveal that such incidences occurred during the period of low traffic demand, $29 \%$ believed that the incidence happened at times of average traffic demand and $10 \%$ asserted that incidences were at periods of high traffic scenario.

\section{Figure 4: Level of safety with traffic complexity}

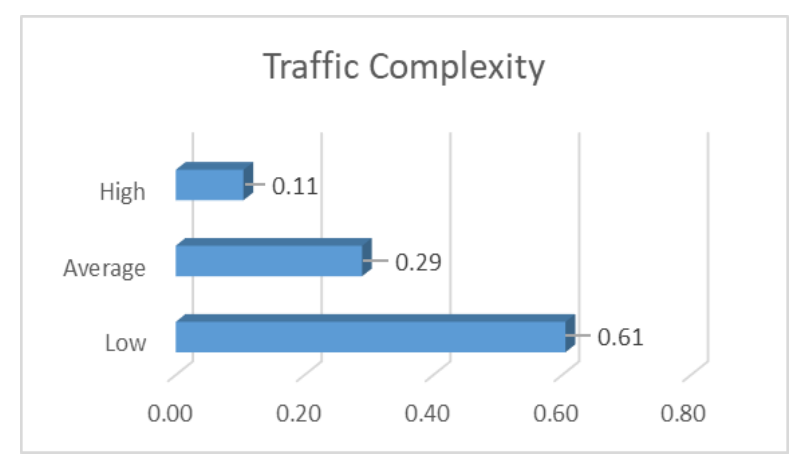

Furthermore, the occurrence of air incidence has a high severity level at departure, and arrival phases of flight, higher likelihood at the radar room and much of the incidences were as a result of faulty equipment and inherent absence of modern airspace infrastructure. Also, in Lagos terminal airspace, the number of incidences has no close correlation with the level of traffic complexity. 


\subsection{Analysis of LOS terminal system delay}

Aircrafts' arrival delays were categorised daily and the delays encountered by arriving aircraft in the respective days summed up in minutes. This is shown in Table 1. Total schedule arrival delay was found to be highest at Wednesday with a figure of 392 minutes, representing an average of 17.9 minutes per aircraft that arrived Lagos airport at that period. In addition, the total approach contact time was found to be highest on Tuesday with a figure of 57 minutes, translating to 7.1 minutes per aircraft. These figures on the average scale are however insignificant as far as operational delay is concerned. Arrival operational delay is measured according to US FAA threshold in terms of a flight arriving within 15 minutes of the scheduled arrival time. Hence, Lagos Terminal airspace was observed to witness small average scheduled arrival delay but no operational delay.

\begin{tabular}{lccccc}
\hline Table 1: Arrival delays & $\begin{array}{c}\text { Total } \\
\text { number of } \\
\text { flight }\end{array}$ & $\begin{array}{c}\text { Average Schedule } \\
\text { Time Delay } \\
\text { (minutes) }\end{array}$ & $\begin{array}{c}\text { Max. Schedule } \\
\text { Time Delay } \\
\text { (minutes) }\end{array}$ & $\begin{array}{c}\text { Average Approach } \\
\text { Contact Time Delay } \\
\text { (minutes) }\end{array}$ & $\begin{array}{c}\text { Max. Approach } \\
\text { Contact Time } \\
\text { Delay } \\
\text { (minutes }\end{array}$ \\
\hline Saturday & 146 & 15.8 & 386 & 4.6 & 53 \\
Sunday & 147 & 12.5 & 315 & 4.8 & 44 \\
Monday & 171 & 14.4 & 255 & 6.5 & 64 \\
Tuesday & 170 & 7.8 & 87 & 5.5 & 57 \\
Wednesday & 170 & 17.9 & 392 & 6.0 & 54 \\
Thursday & 163 & 13.0 & 172 & 6.7 & 49 \\
Friday & 183 & 14.2 & 203 & 52 \\
\hline
\end{tabular}

Source: Authors' Computation 2020

Similarly, the highest total schedule departure delay of 2139 minutes was recorded on Monday, which translates into 31.4 minutes per aircraft. Tuesday had the highest departure average delay of 84.7 minutes per aircraft (see Table 2). This is a pointer to the fact that scheduled departure delay is not connected with excess departure demand since Friday recorded the highest number of flight which was 183. In the same vein, departure fix delays here are measured from the difference of actual departure time with the time the airline acquires ATC clearance. Total departure fix delay was also found to be highest at Monday with a score of 193 minutes translating into 23.8 minutes per aircraft (see table 2). This does not correspond with the day with high departure demand which is Friday. The data of average departure fix delay per aircraft revealed that departure demand is closely related to departure fix delay. Finally, the average schedule departure delay for Lagos airport is about 21.7 minutes per aircraft in a day of optimum airport operation and about 23.3 minutes for average departure fix delay per aircraft.

\begin{tabular}{lccccc}
\hline Table 2: Departure delays & $\begin{array}{c}\text { Total } \\
\text { number of } \\
\text { flight }\end{array}$ & $\begin{array}{c}\text { Average Schedule } \\
\text { Time Delay } \\
\text { (minutes) }\end{array}$ & $\begin{array}{c}\text { Max. Schedule } \\
\text { Time Delay } \\
\text { (minutes) }\end{array}$ & $\begin{array}{c}\text { Average ATC } \\
\text { Contact Time Delay } \\
\text { (minutes) }\end{array}$ & $\begin{array}{c}\text { Max. ATC } \\
\text { Contact Time } \\
\text { Delay } \\
\text { (minutes) }\end{array}$ \\
\hline Saturday & 146 & 19.8 & 242 & 21.7 & 97 \\
Sunday & 147 & 29.0 & 741 & 20.4 & 77 \\
Monday & 171 & 31.4 & 2139 & 23.8 & 193 \\
Tuesday & 170 & 84.7 & 1698 & 24.0 & 97 \\
Wednesday & 170 & 51.7 & 1442 & 21.5 & 87 \\
Thursday & 163 & 47.1 & 1818 & 22.1 & 79 \\
Friday & 183 & 21.7 & 376 & 23.3 & 117 \\
\hline
\end{tabular}

Source: Authors' Computation 2020

\subsection{Analysis of LOS terminal airspace system predictability}

As noted earlier, system predictability indicates whether there is substantial time variability associated with a specific phase of flight. The study is restricted to only arrival and departure times' variability. Predictability of schedule is just essential to an aviation service provider as the reduction of 
delays (though less relevant to other classes of users). Predictability is usually measured as the variation in some kind of movement time. To minimise the effect of weather, a single day is analysed at a time.

As noted earlier, these metrics indicate whether there is considerable time variability associated with a specific phase of flight. Also, variations from the time the aircraft make approach contact (contact time) to the time the aircraft landed at the Lagos airport was investigated. A category analysis of variability of arrival times across the various days at Lagos is shown in Table 2 . It could be deduced that $56.8 \%$ of flights on Saturday to Lagos witnessed arrived on time from the expected time of arrival published in the official airline guide (OAG). Also, $17.8 \%$ of various flights arrived at the airport on time after making approach contact at the approach control centre. Table 3 gives a striking impression of the various arrival variability times at Lagos airport. However, variability in arrival time of 1-5 minutes is common from published airline arrival scheduled time. In the same vein, the variability of 1-5 minutes is common from approach contact times of aircraft. These figures indicate sound arrival predictability signature for Lagos airport.

Table 3: Arrival predictability signature

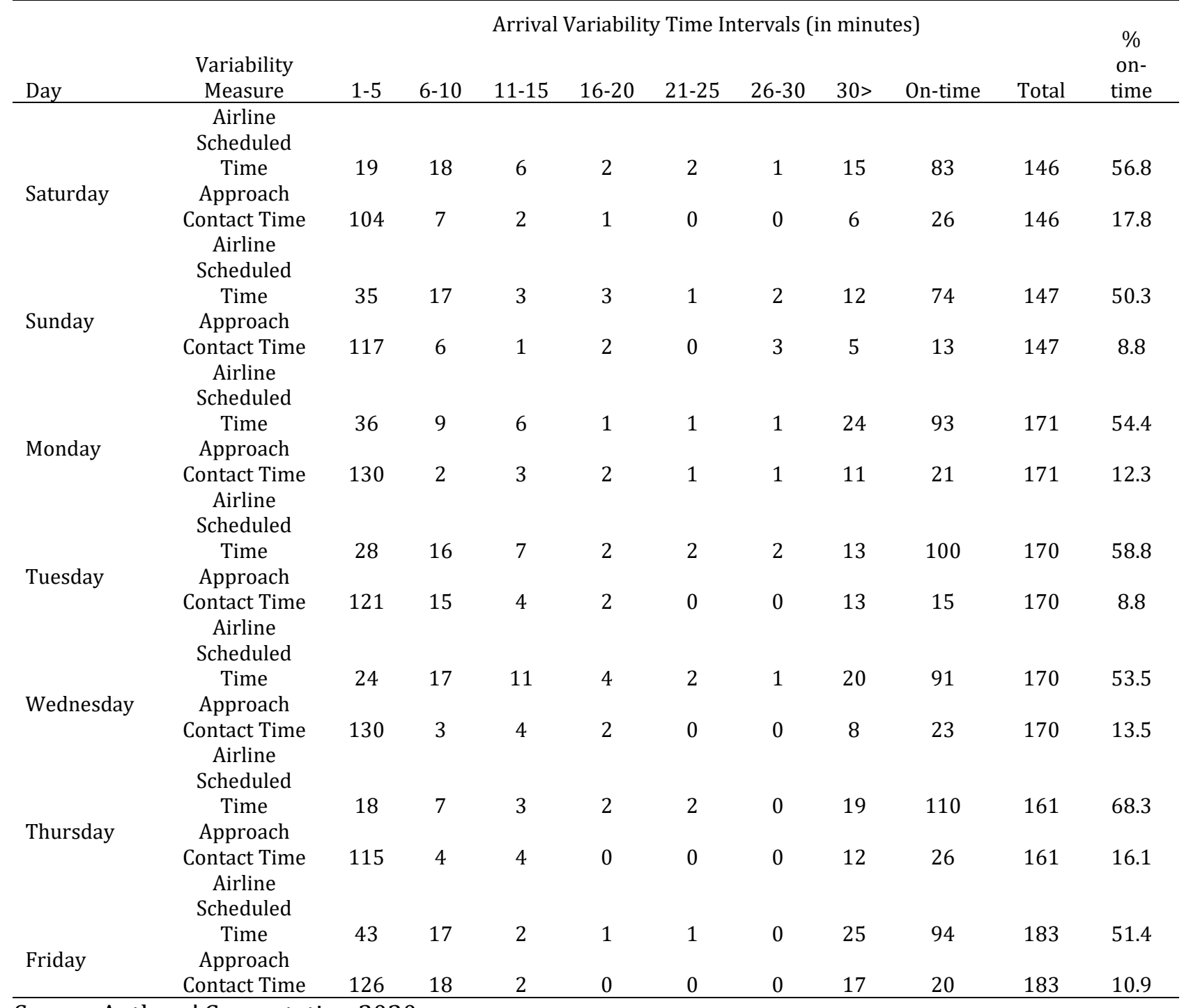

Source: Authors' Computation 2020

As noted earlier, these metrics indicate whether there is a large variability of departure time associated with a specific phase of flight. Departure times from Lagos airport to various routes as arrival time variability were also applied. Variations from the time the aircraft are scheduled to depart and the time ATC clearance is acquired to the actual departure times was investigated. Also, a classification analysis shown in the Table below reveals more considerable time variability above 15 minutes from the stipulated times of scheduled departure and clearance. According to Table 4,58.2\% of departure 
flights across the various routes on Saturday left the Lagos airport on time after the scheduled departure time. Thus less than $50 \%$ of departure flights experience departure time variability ranging from 1-85 minutes on the average. This represents a significant departure time variability from airlines scheduled departure time. Also, departure time variability above 30 minutes is familiar from the ATC clearance time for the various routes under study. However, there is about or more $25 \%$ variability of more than 15 minutes, and this indicates possible inconsistency of predicting departure times from the times ATC clearance was acquired. Above all, the predictability of departure times in Lagos airport is poor compared to those of the arrival. Taken by it, this may be a sign of airspace congestion or ATC deficiencies at the Lagos airport.

Table 4: Departure Predictability Signature

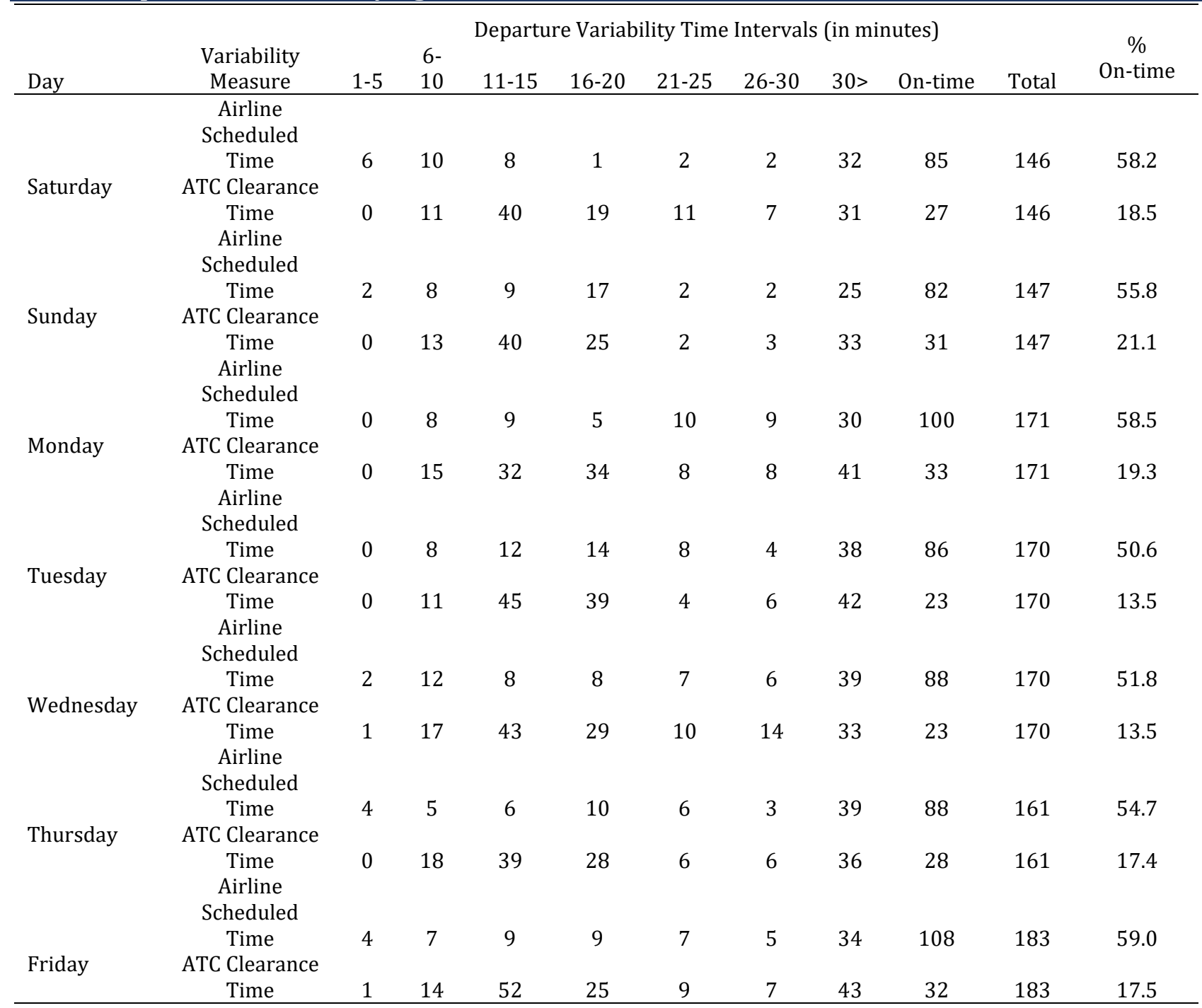

Source: Authors' Computation, 2020

\section{Conclusion}

The level of safety associated with the Lagos terminal airspace is closely associated with departure phase of flight, type of control, equipment malfunction, aircraft holding in position, training of ATM personnel, and insignificantly related with the level of traffic complexity. Hence due to the manual approach to ATC functions and obsolete equipment in use for terminal airspace management responsibility, the safety of the terminal airspace is bleak. The predictability signature at the departure phase of flight at the Lagos airport is poor. This is an indication of the lack of users' confidence in Nigeria's air transport industry to deliver just-in-time service. 


\section{Citation information}

Ejem, E. A., Ikeogu, V. N., Okafor, C. L., \& Erumaka, P. O. (2020). Performance evaluation of terminal airspace system safety, delay and predictability of Muritala Mohammed International Airport, Ikeja Lagos, Nigeria. Journal of Sustainable Development of Transport and Logistics, 5(2), 62-72. doi:10.14254/jsdtl.2020.5-2.6

\section{References}

Adler, N., Liebert, V., \& Yazhemsky, E. (2013a). Benchmarking airports from a managerial perspective. Omega 41, 442-458. http://doi.org/10.1016/j.omega.2012.02.004.

Bjorn Syren (2003). Delays report over ACARS; published in SAS data-link system Bureau of Transportation Statistics (BTS) (2002).

Chang, Y. H., Shao, P. C., \& Chen, H. J. (2015). Performance evaluation of airport safety management systems in Taiwan. Safety Science, 75, 72-86.

Ejem, A. E. (2005). Terminal Airspace Management Performance Metrics in Nigeria (A Case Study of Murtala Mohammed International Airport, Ikeja, Lagos) (Doctoral dissertation, Federal University of Technology, Owerri).

Enoma, A., \& Allen, S. (2007). Developing key performance indicators for airport safety and security. Facilities, 25(7), 296-315. http://doi.org/10.1108/02632770710753334.

Enoma, A., Allen, S., \& Enoma, A. (2009). Airport redesign for safety and security: Case studies of three Scottish airports. International Journal of Strategic Property Management, 13(2), 103-116. http://doi.org/10.3846/1648-715X.2009.13.103-116.

Federal Aviation Administration. (2001). Aviation Delays in 2000; a publication of Federal Aviation Administration, USA. January 31.

Federal Aviation Administration. (2002). Monthly Summary of Air Traffic activity and Delays in the National Airspace System; a publication of Federal Aviation Administration, USA.

Bezerra, G. C., \& Gomes, C. F. (2018). Performance measurement practices in airports: Multidimensionality and utilization patterns. Journal of Air Transport Management, 70, 113-125.

Gillen, D., \& Morrison, W. G. (2015). Aviation security: Costing, pricing, finance and performance. Journal of Air Transport Management, 48, 1-12. http://doi.org/10.1016/j.jairtraman. 2014.12.005.

Humphreys, I., \& Francis, G. (2002). Performance measurement: a review of airports. International journal of transport management, 1(2), 79-85. Retrieved from. http://dc433.4shared.com/doc/ jADMNRRP/preview.html.

Lai, P. L., Potter, A., \& Beynon, M. (2012). The development of benchmarking techniques in airport performance evaluation research. Transportation Journal, 51(3), 305-337.

Lai, P. L., Potter, A., Beynon, M., \& Beresford, A. (2015). Evaluating the efficiency performance of airports using an integrated AHP/DEA-AR technique. Transport Policy, 42, 75-85.

Obinani, I. M. (2002). Current Search and Rescue in Airline Operations in Nigeria and Prospects for the $21^{\text {st }}$ Century, unpublished MBA Thesis, Department of Transport Management Technology, Federal University of Technology, Owerri, Nigeria.

Okeudo, G. N., \& Ejem E. A. (2009). Arrival and Departure Delay Characteristics in Nigerian Airlines (A Case Study of Port Harcourt Airport). Journal of Research in National Development, 7(1).

Pacheco, R. R., Fernandes, E., \& Domingos, E. M. (2014). Airport airside safety index. Journal of Air Transport Management, 34, 86-92. http://doi.org/10.1016/j.jairtraman.2013.08.007.

Wang, P. T., Schaefer, L. A., \& Wojcik, L. A. (2003, October). Flight connections and their impacts on delay propagation. In Digital Avionics Systems Conference, 2003. DASC'03. The 22nd (Vol. 1, pp. 5-B). IEEE.

Roelen, A., \& Blom, H. A. (2013). Airport safety performance. Modelling and Managing Airport Performance, 171-208. http://doi.org/10.1002/9781118535844.ch7. 
Sarkis, J. (2000). An analysis of the operational efficiency of major airports in the United States. Journal of Operations management, 18(3), 335-351. http://doi.org/10.1016/S0272-6963 (99) 00032-7.

Yoshida, Y., \& Fujimoto, H. (2004). Japanese-airport benchmarking with the DEA and endogenousweight TFP methods: testing the criticism of overinvestment in Japanese regional airports. Transportation Research Part E: Logistics and Transportation Review, 40(6), 533-546. http://doi.org/10.1016/j.tre.2004.08.003. 


\section{Appendix}

\section{Table 5: Summary of terminal airspace safety assessment instrument}

\begin{tabular}{|c|c|c|c|}
\hline Factor & Assessment Criterion & Frequency & Quality Weight \\
\hline \multirow[t]{3}{*}{ Type of incidence } & Operational error & 23 & 0.40 \\
\hline & Operational deviation & 18 & 0.32 \\
\hline & Others & 16 & 0.28 \\
\hline \multirow[t]{9}{*}{ Flight profile } & Departure & 13 & 0.31 \\
\hline & Touching down & 1 & 0.02 \\
\hline & Making the approach & 7 & 0.17 \\
\hline & Level flight & 2 & 0.05 \\
\hline & Taxiing & 1 & 0.02 \\
\hline & Take off & 3 & 0.07 \\
\hline & Landing & 3 & 0.07 \\
\hline & Climbing & 6 & 0.14 \\
\hline & Holding in position & 9 & 0.21 \\
\hline \multirow[t]{6}{*}{ Position function } & Radar & 13 & 0.33 \\
\hline & Flight data & 1 & 0.03 \\
\hline & Clearance delivery & 6 & 0.15 \\
\hline & Ground control & 5 & 0.13 \\
\hline & Departure position & 7 & 0.18 \\
\hline & Arrival position & 7 & 0.18 \\
\hline \multirow[t]{2}{*}{ Training } & Training 12 months before incidence (Yes) & 17 & 0.45 \\
\hline & Training 12 months before incidence (No) & 21 & 0.55 \\
\hline \multirow[t]{2}{*}{ Cause of incidence } & Equipment & 22 & 0.58 \\
\hline & Non-equipment & 16 & 0.42 \\
\hline \multirow[t]{3}{*}{ Type of control } & Radar & 15 & 0.39 \\
\hline & Tower & 17 & 0.45 \\
\hline & Non-radar & 6 & 0.16 \\
\hline \multirow[t]{3}{*}{ Traffic Complexity } & Low & 23 & 0.61 \\
\hline & Average & 11 & 0.29 \\
\hline & High & 4 & 0.11 \\
\hline
\end{tabular}

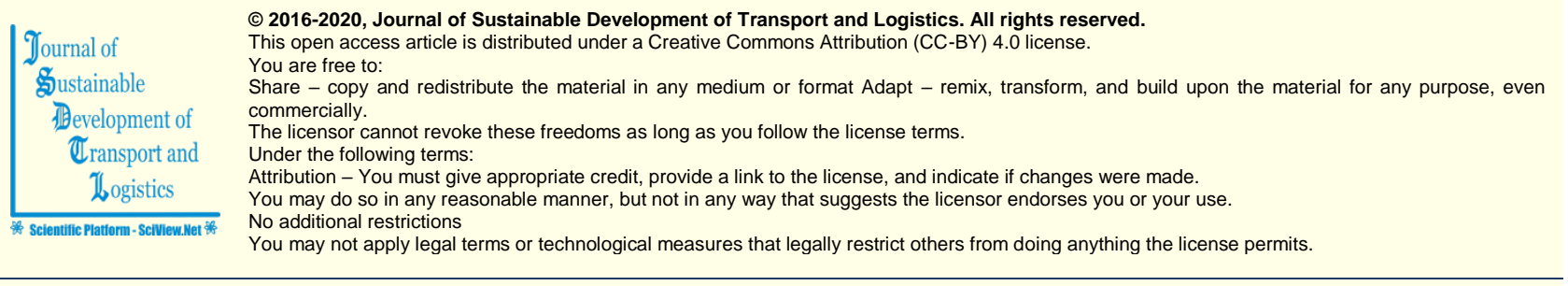

Journal of Sustainable Development of Transport and Logistics (ISSN: 2520-2979) is published by Scientific Publishing House "CSR", Poland, EU and Scientific Publishing House "SciView", Poland, EU

Publishing with JSDTL ensures:

- Immediate, universal access to your article on publication

- High visibility and discoverability via the JSDTL website

- Rapid publication

- Guaranteed legacy preservation of your article

- Discounts and waivers for authors in developing regions

Submit your manuscript to a JSDTL at https://jsdtl.sciview.net/ or submit.jsdtl@sciview.net 